\title{
Sickness absence levels and personality inventory scores
}

\author{
R. W. HOWELL ${ }^{1}$ and SIDNEY CROWN \\ United Kingdom Atomic Energy Authority and Department of Psychiatry, \\ The London Hospital, London E1
}

\begin{abstract}
Howell, R. W., and Crown, Sidney (1971). Brit. J. industr. Med., 28, 126-130. Sickness absence levels and personality inventory scores. A 'personality inventory', the Middlesex Hospital Questionnaire (MHQ), was fully completed by 2352 participants in a prospective survey of heart disease undertaken by the medical service of the United Kingdom Atomic Energy Authority (UKAEA). All participants were male employees born between 1912 and 1926. MHQ scores were analysed to see if there was any association between score levels and various causes of absence from work attributed to sickness.

MHQ scores were significantly higher than the survey mean in patients suffering from some diseases regarded as 'psychosomatic' (peptic ulcer, $P<0.05$; duodenal ulcer, $P<0.01$; hay fever, bronchial asthma, and allergy, $\mathrm{P}<0.05$; essential hypertension, $\mathrm{P}<0.01$ ). Mean MHQ scores were also higher than the survey mean in patients who lost time from work because of mental, psychoneurotic, and personality disorders $(\mathbf{P}<0.001)$. There was a greater percentage of absenteeism $(78.7 \%)$ in high MHQ scorers than in low scorers $(71.7 \%$, $\mathbf{P}<0.001$ ); the total time lost was also greater in those with high scores.

The uses and limitations of such a personality inventory as a screening or research device in industry are discussed.
\end{abstract}

A prospective survey of heart disease was begun in January 1967 at four establishments of the United Kingdom Atomic Energy Authority (UKAEA). The survey was confined to men, chosen by random methods, born between 1912 and 1926; fewer than $10 \%$ of those selected declined to participate. In addition to a medical history, annual clinical examination, electrocardiogram, chest radiograph, and various laboratory tests, the 2700 participants were asked to complete the Middlesex Hospital Questionnaire (MHQ) (Crown and Crisp, 1966, 1970). The MHQ is a short (10-minute) self-rating scale of psychoneurotic symptoms and traits comprising six sub-tests. These sub-tests are called 'free-floating' anxiety (fear without an object), phobic anxiety (fear of specific objects or situations),

'Present address: British Steel Corporation, 33 Grosvenor Place, London SW1. obsessionality (orderliness, meticulousness, conscientiousness), somatic anxiety (breathlessness, dizziness, etc.), depression (sad mood), and hysteria (personality traits such as fondness for display, shallow emotional feeling, etc.).

A previous paper based on a large sample from this survey (Crown, Duncan, and Howell, 1970) gave extensive standardization data for this personality test. It showed that $15 \%$ of the survey group failed to answer all 48 questions, but that over $99 \%$ of the total expected answers were provided; $95 \%$ of the questionnaires had 47 or 48 completed questions. It was also found that the average score under each sub-test was not affected (to one decimal place) whether all the questionnaires or only the completed ones were used, provided that the blank columns of incomplete questionnaires were scored by adding the average score of the completed columns in the same sub-test. As it was easier, using a standard 
computer program, to calculate means and standard deviations from fully completed forms, incomplete questionnaires have been discarded in this paper, leaving 2352 men for review.

Sickness absence data for all UKAEA staff are maintained on magnetic tape, so that a computer search for the sickness absence experience of the participants in the survey, during the five years 1964-68, was readily carried out. Sickness absence is defined as absence from work supported by a medical certificate. Non-manual employees were required to submit medical certificates for all absences attributed to sickness lasting more than four days and manual workers for all absences. In practice there were few certificated absences lasting less than four days, and since this type of absence is generally regarded as of the ipse dixit type, all such absences have been omitted from this study.

\section{Results}

'Nervous breakdowns', 'fainting and blackouts' As part of their personal and family history, patients were given a standard questionnaire which asked, inter alia, whether they had ever had a nervous breakdown or had lost any time through nervous illness, and whether or not they had ever suffered from fainting attacks and 'blackouts'. It was felt that if the MHQ were effective as a predictor of those with present or future psychiatric problems, it should, albeit to a lesser degree, reflect past problems. Obviously the individual's previous nervcus illness could cover many trivial ailments, mostly transient and effectively reversible; for this reason one would not expect the scores to approach those of current piychiatric outpatients. Nevertheless the scores might well tend to be significantly above average. Table 1 shows that both 'nervous disease' and 'fainting' groups had total scores, and scores in most sub-tests, which were statistically highly significantly different from the survey means. The questionnaire may have a valid discriminatory function; there is some suggestion that fainting and 'blackout' episodes have a psychosomatic element. Psychosomatic is used in this paper in the context of disease of multifactorial aetiology in which psychological factors, among others, are important. That there is a physical basis in some of the diseases considered cannot be doubted; nor can one doubt that psychological factors may also be involved.

\section{Illnesses associated with personality traits}

Sickness absence records were machine scrutinized to identify survey men who had lost time from work through illness which might be associated with personality traits. Some diseases (e.g., ulcerative colitis) produced too few cases for useful analysis, and for this reason a minimum of 10 patients was the criterion for inclusion in Table 2. The MHQ was used approximately halfway through the sickness period under review, so that absences are partly retrospective and partly prospective in relation to the scores obtained.

In view of the relatively small numbers in any one disease group in Table 2, these groups have not been deducted from the mean for all survey men. This has the advantage of using one standard set of figures with which the averages for the various disease groups can be compared.

It is of interest that the mean scores of patients who have lost working time as a result of certain diseases regarded as psychosomatic (gastric and duodenal ulcer, hay fever, bronchial asthma, allergies, essential hypertension) show significant differences on the MHQ from the control survey patients, as do the scores of those who have lost working time for mental, psychosomatic, and personality disorders. Certain insignificant relationships are surprising-migraine (a group of only 10 persons) and accidents (occupational and non-occupational).

\section{Sickness absence}

Of the $\mathbf{2} 352$ men fully completing the questionnaire, $124(5.3 \%)$ were not employed during the full five-

TABLE 1

Mean Scores for Total Survey Population and for 'Nervous Disease' and 'Fainting' Sub-groups

\begin{tabular}{|c|c|c|c|c|c|c|c|c|}
\hline \multirow{2}{*}{ Group } & \multirow{2}{*}{$\begin{array}{c}\text { No. of } \\
\text { men }\end{array}$} & \multicolumn{7}{|c|}{ Mean scores } \\
\hline & & Anxiety & Phobia & Obsession & Soma & Depression & Hysteria & Total \\
\hline $\begin{array}{l}\text { 'Nervous } \\
\text { disease' }\end{array}$ & 183 & $5 \cdot 5^{3}$ & $3 \cdot 1^{3}$ & $7 \cdot 7^{3}$ & $5 \cdot 1^{3}$ & $3 \cdot 8^{3}$ & $3 \cdot 1^{1}$ & $28 \cdot 4^{3}$ \\
\hline 'Fainting' & 167 & $4 \cdot 3^{3}$ & $2 \cdot 7$ & $7 \cdot 2^{2}$ & $5 \cdot 1^{2}$ & $3 \cdot 1^{2}$ & $2 \cdot 8$ & $25 \cdot 2^{3}$ \\
\hline All survey men & 2352 & $2 \cdot 7$ & $2 \cdot 3$ & $6 \cdot 4$ & $3 \cdot 8$ & $2 \cdot 4$ & $2 \cdot 6$ & $20 \cdot 1$ \\
\hline
\end{tabular}

'Significantly different from mean of all survey men at 0.05 level.

'Significantly different from mean of all survey men at 0.01 level.

${ }^{3}$ Significantly different from mean of all survey men at 0.001 level. 
TABLE 2

Average MHQ Scores of Patients who have lost Working Time as a result of Certified Specified Diseases COMPared WITH Means for 2352 SURVey Patients

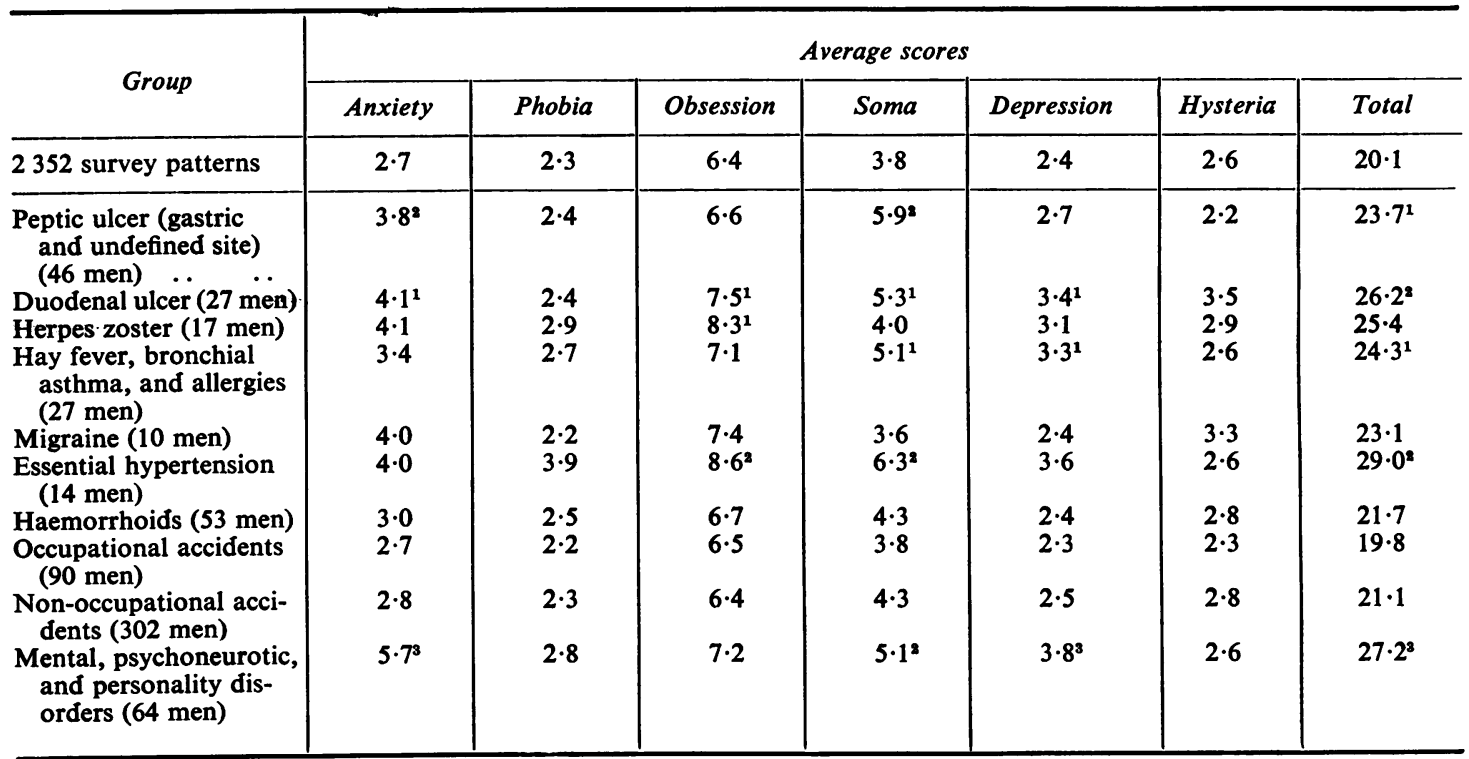

'Significantly different from survey mean at 0.05 level.

2Significantly different from survey mean at 0.01 level.

'Significantly different from survey mean at $\mathbf{0 . 0 0 1}$ level.

year period under review (1964-8) and these men have been excluded from subsequent analyses. It was thought that a useful basis for analysis of the relationship (if any) of MHQ scores and sickness absence would be a comparison of the highest scoring $15 \%$ of the men on each personality trait with the lowest scoring $15 \%$. The highest scoring $15 \%$ in each personality test did not take in the same men, though some men had scores high enough to qualify them for inclusion in more than one sub-test analysis. An advantage of having rotating groups in the subtest high scores was that the mean score for each personality trait was likely to be as high as the average for Crown and Crisp's (1966) psychoneurotic outpatients. This figure of $15 \%$ was arbitrarily applied so that there was no exclusion of some men with equal scores to obtain a precise proportion. For example, the 305 men with a total score of 33 or more comprise only $13.7 \%$ of the available men. Altering the criterion to take in men scoring 32 or more would have resulted in the inclusion of $16.8 \%$ of the men. The minimum score of 33 was therefore used as this gave a sample nearer to $15 \%$ of the total than did the lower threshold of 32 . The lowest $15 \%$ group was selected in a similar manner.

Table 3 shows that all high-scoring sub-tests except hysteria were associated with significantly higher
TABLE 3

PerCentage of 'High-SCORING' AND 'Low-SCORING' MEN WITH SICKNESS ABSENCE 1964-8

\begin{tabular}{|c|c|c|c|}
\hline \multicolumn{2}{|c|}{ Trait } & High-score men & Low-score men \\
\hline $\begin{array}{l}\text { Anxiety } \\
\text { Phobia } \\
\text { Obsession } \\
\text { Soma } \\
\text { Depression } \\
\text { Hysteria }\end{array}$ & $\begin{array}{l}\ldots \\
\ldots \\
\cdots \\
\cdots \\
\ldots\end{array}$ & $\begin{array}{l}77 \cdot 9 \\
76 \cdot 4 \\
76 \cdot 3 \\
78 \cdot 1 \\
76 \cdot 3 \\
72 \cdot 7\end{array}$ & $\begin{array}{l}70 \cdot 3^{1} \\
67 \cdot 3^{2} \\
66 \cdot 2^{2} \\
66 \cdot 7^{3} \\
69 \cdot 2^{1} \\
77 \cdot 9\end{array}$ \\
\hline Total score & & $78 \cdot 7$ & $71 \cdot 7^{3}$ \\
\hline
\end{tabular}

${ }^{1}$ Significantly different from high-score percentage at $\mathbf{0 . 0 5}$ level.

'Significantly different from high-score percentage at 0.01 level.

${ }^{3}$ Significantly different from high-score percentage at $\mathbf{0 . 0 0 1}$ level.

absence rates than occurred among the low-scoring men. The hysteria result could be due to chance but an interesting finding is that men who had neither high nor low scores for this sub-test (i.e., $70 \%$ of the men) gave rise to a sickness rate of $70.1 \%$ (lower than either of the $15 \%$ groups). For all other sub- 
tests, the remaining men had results falling between the high- and low-scoring groups.

\section{MHQ score and frequency of absence}

As the total MHQ score appeared from Table 3 to be as good a discriminator as any sub-test, the remaining Tables are based on the high and low total scores. Although the higher percentage of absentees in high-scoring men is of interest to industry, the real cost is in the total time lost. This is derived from the number of absences and the average length of absence. Not only did the men with a high total score have a higher percentage with sickness absence but they also had more episodes of sickness-923 episodes (3.0 per man at risk) against 576 (1.9 per man at risk) in the men with a low total score. The days lost per 100 workers per annum were respectively 1409 and 658 , and the average lengths of absence were 23.3 and $17 \cdot 7$ calendar days.

Table 4 shows that the difference in the distribution of sickness episodes is highly significant.

TABLE 4

Distribution of Sickness Episodes in High Total SCORE AND LOW TOTAL SCORE MeN: 1964-8

\begin{tabular}{c|cccccc|c}
\hline & \multicolumn{7}{|c}{$\begin{array}{c}\text { No. of men with aggregate no. } \\
\text { of episodes shown }\end{array}$} \\
\cline { 2 - 7 } & 0 & 1 & 2 & 3 & 4 & $\begin{array}{c}5 \text { or } \\
\text { more }\end{array}$ & Total \\
\hline $\begin{array}{c}\text { Low total } \\
\text { score } \\
\begin{array}{c}\text { High total } \\
\text { score }\end{array}\end{array}$ & 103 & 89 & 43 & 26 & 18 & 31 & 310 \\
\hline Total & 65 & 53 & 46 & 43 & 29 & 69 & 305 \\
\hline & 168 & 142 & 89 & 69 & 47 & 100 & 615 \\
\hline & $\chi^{2}=38.97$ & DF $=5$ & $\mathrm{P}=<0.01$
\end{tabular}

MHQ scores and disease groupings

Although Table 2 suggested a correlation between certain possibly psychosomatic diseases and high scores, the incidence of these particular diseases was not high enough to account for the marked difference in sickness experience between the highand low-scoring men in Table 4. Table 5 shows the experience of the high- and low-scoring groups; clearly the disease groups are not mutually exclusive and some men appear in more than one disease group. The high-scoring men had a higher proportion of sick men in all disease groups excepting those relating to accidents, poisoning and violence, and diseases of the bones and organs of movement.

\section{Discussion}

Much of the emphasis of occupational medicine is changing from the study of the direct effects of physical work on health to the consideration of the inter-relationships between the total work environment-physical, social, and psychological-and the 'whole man', mental and physical. The literature in this field has recently been extensively reviewed (Baker, McEwan, and Sheldon, 1969). The present paper can be seen as an attempt to find a method to enable further quantitative study into one aspect of this multifactorial problem.

It appears that this brief personality inventory may have some value as a predictor of sickness experience leading to absence from work, although there are certain unexpected findings which may reflect the limitations of the MHQ, which may be artefacts peculiar to this series of observations, or may suggest certain topics (e.g., accident 'proneness') worthy of further research.

The overall total score is shown to correlate well with some diseases which would be expected to be influenced by, or to reflect, personality traits. This

TABLE 5

Percentage of Men with Sickness Absence in the High- and low-Scoring Categories Classified BY DiseASe Groups

\begin{tabular}{|c|c|c|c|c|c|c|c|c|c|c|}
\hline \multirow[b]{2}{*}{ Category } & \multicolumn{10}{|c|}{ Disease group } \\
\hline & $\begin{array}{l}\text { Circu- } \\
\text { latory } \\
\text { system }\end{array}$ & $\begin{array}{c}\text { Digestive } \\
\text { system }\end{array}$ & $\begin{array}{l}\text { Respi- } \\
\text { ratory } \\
\text { system }\end{array}$ & $\begin{array}{c}\text { Genito- } \\
\text { urinary } \\
\text { system }\end{array}$ & $\begin{array}{l}\text { Mental, } \\
\text { psycho- } \\
\text { neurotic } \\
\text { \& person- } \\
\text { ality }\end{array}$ & $\begin{array}{c}\text { Skin } \\
\text { diseases }\end{array}$ & $\begin{array}{l}\text { Bones and } \\
\text { organs of } \\
\text { movement }\end{array}$ & $\begin{array}{l}\text { Accidents, } \\
\text { poisoning } \\
\text { \& violence }\end{array}$ & $\begin{array}{l}\text { Symptoms, } \\
\text { ill-defined } \\
\text { disease }\end{array}$ & $\begin{array}{c}\text { All } \\
\text { other } \\
\text { causes }\end{array}$ \\
\hline $\begin{array}{l}\text { High } \\
\text { score }\end{array}$ & $11 \cdot 8^{1}$ & $25 \cdot 6^{1}$ & $56 \cdot 4^{3}$ & $6 \cdot 6^{3}$ & $5 \cdot 2^{3}$ & $4 \cdot 3$ & $14 \cdot 4$ & $15 \cdot 1$ & $16 \cdot 7^{2}$ & $16 \cdot 1$ \\
\hline $\begin{array}{l}\text { Low } \\
\text { score }\end{array}$ & $5 \cdot 8$ & $17 \cdot 1$ & $40 \cdot 0$ & $1 \cdot 6$ & 0.6 & $3 \cdot 2$ & $14 \cdot 8$ & $17 \cdot 4$ & $8 \cdot 1$ & $11 \cdot 0$ \\
\hline
\end{tabular}

${ }^{1}$ Differs significantly from the low-score group at 0.05 level. ${ }^{2}$ Differs significantly from the low-score group at 0.01 level. ${ }^{3}$ Differs significantly from the low-score group at 0.001 level. 
is true of sub-test scores also, except for the particular values under the heading 'hysteria' which neither correlate with symptoms, such as fainting or other nervous complaints, nor show any significant relationship to diseases which might be thought to have psychosomatic components. This is not so surprising as it might at first appear for, as discussed earlier (Crown et al., 1970), this scale is not intended as a measure of clinically manifest hysteria, but of hysterical personality traits such as shallowness of emotion, desire to attract attention. and a fondness for display.

Those men with many absence episodes and generally higher scores than the average not only had an excess of those diseases which might be classed as psychosomatic but also absented themselves under a wide and varied range of diagnoses.

The suggestion that there might be a relationship between high scores on tests of psychoneurotic instability and sickness absence is not new. Stewart (1965) used a personality questionnaire with 172 female student nurses and related the results to frequency of physical illness. That study showed the high frequency group to be less emotionally stable and more tense, which agrees with our findings. Thurlow (1967) reviewed the general question of susceptibility to illness. He noted that illness tends to be concentrated among a relatively small percentage of persons, and tends to occur during discrete intervals of time, that is, in 'clusters'. In considering underlying reasons for these findings, complex psychosocial factors relating to people's total life situation, including their jobs, are suggested. Among these, emotional and personality factors are relevant, particularly to illness reporting. He distinguishes between 'illness behaviour' and 'illness as such', a research area that could well be investigated further in the United Kingdom.

The pattern of absence which is attributed to sickness is not determined by sickness alone (Duncan and Howell, 1970; Howell, 1968). There are social, economic, morale, and other emotional factors which may be very complex. It is interesting, however, that varying levels of sickness absence at different UKAEA establishments do not affect the general picture. For instance, the Harwell absence rates were considerably lower than those at the other establishments, but high scorers, even at Harwsll, followed the overall pattern and were associated with absence rates higher than those of the lower scorers.

While the correlations of groups appear to have some validity, there are individuals with high total scores who have little or no sickness experience of any kind. This limits the value of the MHQ as an occupational screening device but, as it is easy to apply, it may have a place as a coarse filter or to suggest a fuller enquiry.

It is perhaps surprising that accidents-occupational and otherwise-do not give a significant correlation with inventory scores, either total or on individual scales. This may give some support to the belief that 'arcident proneness'-if it exists at all-is a transient phenomenon, at least in some people. It may, for example, relate to response to stress rather than to basic personality traits as covered by a personality inventory such as the MHQ. This is an important area for further research.

We are grateful to Dr. K. P. Duncan, Chief Medical Officer, British Steel Corporation, for very considerable assistance with the manuscript, and to Dr. G. B. Schofield, Dr. J. C. Evans, Dr. A. M. Leach, and Dr. D. Wilson and their associates who did so much work at Windscale, Harwell, Springfields, and Dounreay.

\section{References}

Baker, F., McEwan, P. J. M., and Sheldon, A. (Eds) (1969). Industrial Organizations and Health. Tavistock Publications, London.

Crown, S., and Crisp, A. H. (1966). A short clinical diagnostic self-rating scale for psychoneurotic patients: The Middlesex Hospital Questionnaire (MHQ) Brit. J. Psychiat. 112, 917-923.

- and - (1970). The Middlesex Hospital Questionnaire (MHQ) Manual. Psychological Test Publications, Barnstaple.

- Duncan, K. P. B., and Howell, R. W. (1970). Further evaluation of the Middlesex Hospital Questionnaire (MHQ). Brit. J. Psychiat., 116, 33-7.

Duncan, K. P., and Howell, R. W. (1970). Health of workers in the United Kingdom Atomic Energy Authority. Hlth Phys., 19, 285.

Howell, R. W. (1968). In Proceedings of the Symposium on Absence from Work Attributed to Sickness, edited by A. W. Gardner, Society of Occupational Medicine, London.

Stewart, H. (1965). The relationship of physical illness to the IPAT 16 personality factors test. J. clin. Psychol., 21, 264-6.

Thurlow, H. J. (1967). General susceptibility to illness: a selective review. Canad. med. Ass. J., 97, 1397-1404.

Received for publication June 2, 1970. 